\title{
Reduced cholesterol is associated with the depressive-like behavior in rats through modulation of the brain 5-HT1A receptor
}

\author{
Shuqin Sun ${ }^{1}$, Shuo Yang ${ }^{2 *}$, Yongjun Mao ${ }^{1}, X_{i u j u a n} \mathrm{Jia}^{1}$ and Zheng Zhang ${ }^{1}$
}

\begin{abstract}
Background: Low serum cholesterol levels are related to an increased risk of depression and its serious consequences. However, the effect of central cholesterol on depressive disorder and its potential regulatory mechanism is poorly understood. Therefore, brain cholesterol in patients with depression may not only decrease the risk for developing this disease but also increase the beneficial effects of treatment for depression.

Methods: In current study, rats were exposed to chronic mild stress (CMS) for consecutive 28 days, and the depressive-like behavior was tested by sucrose preference test, immobility in the forced swim test, locomotor activity in the open field test, decreased bodyweight and food intake. Additionally, the total cholesterol levels in the medial prefrontal cortex (mPFC) and the hippocampus of rats were measured by gas chromatograph mass spectrometer. Finally, 5-HT1A receptor antagonist WAY100635 was used to determine the potential role of serotonin system in the interaction between central cholesterol and depression.

Results: CMS significantly reduced total cholesterol levels in the MPFC but not in the hippocampus and resulted in depressive-like behavior. Chronic supplementation of cholesterol by food reversed the depressive-like behavior induced by CMS. Furthermore, pre-injection of 5-HT1A receptor antagonist WAY100635 into the mPFC blocked the treatment effects of cholesterol on the reversal of behavioral response.

Conclusion: This finding suggested that cholesterol in the MPFC may have an impact on the sensitivity of the 5-HT1A receptor in the development and treatment of depression. The treatment benefits of cholesterol could be through modulation of the brain 5-HT1A receptor.
\end{abstract}

Keywords: Cholesterol, Depression, Serotonin, Chronic stress, Medial prefrontal cortex

\section{Introduction}

Individuals with serious mental illness are at increased risk for coronary artery disease. Acute coronary syndrome significantly decreases total cholesterol levels [1]. Aberrant lipid metabolism has also been observed in coronary artery disease patients with or without depression [2,3], as well as those with depression who are otherwise medically healthy $[4,5]$, suggesting that lipid signaling plays a key role in the comorbidity. Patients with major depressive disorder (MDD) may have significant differences in cholesterol levels

\footnotetext{
* Correspondence: yangs_ahqu@163.com

${ }^{2}$ Department of the Intensive Care Unit, The Affiliated Hospital of Qingdao University, 16, Jiangsu Road, Qingdao, Shandong Province 266000, China Full list of author information is available at the end of the article
}

compared to healthy controls [6]. Accumulating evidence suggests that low serum total cholesterol levels related to an increased risk of depression and its serious consequences [7]. Most recently, low serum cholesterol levels have also been associated with suicidal behavior [8-11]. However, the effect of central cholesterol on depressive disorder is poorly understood.

It has been proposed that brain synaptosomal membrane cholesterol might determine the number of serotonin receptors [8]. Low membrane cholesterol decreases the number of serotonin receptors. Therefore, disturbed cholesterol levels may be associated with serotonergic dysfunction. There are ample evidences for a critical involvement of serotonergic receptors, particularly 5-HT1A, in the pathophysiology and 
treatment of depression [12,13]. In preclinical studies, 5HT1A agonists increase prefrontal dopamine release [14,15]. As a consequence, the 5-HT1A receptor serves as an important target in the development of therapeutic agents for neuropsychiatric disorders such as anxiety and depression [16]. Previous study has demonstrated the requirement of membrane cholesterol in the organization, dynamics, and function of the 5-HT1A receptor [17,18]. Additionally, it has been shown that there is a significant reduction in the level of specific ligand binding and G-protein coupling to 5-HT1A receptors upon chronic cholesterol depletion, although the membrane receptor level is not reduced at all [18]. Therefore, we hypothesized that 5-HT1A receptors could be involved in the induction of depression by chronic mild stress through cholesterol reduction. Recent neuroimaging and medial post-mortem studies showed altered activity of discrete regions within the hippocampus and prefrontal cortex (mPFC) and their atrophy are associated with depression [19-21]. In addition, 5-HT1A heteroreceptors are abundantly expressed post-synaptically in the PFC, amygdala, and hippocampus to mediate serotonin actions on fear, anxiety, stress, and cognition, indicating a primary role of the 5-HT-PFC circuitry in effective treatment of depression [22-24].

Based on these findings, the present study examines whether the changes of brain cholesterol levels are involved in the depressive symptoms in chronic mild stress procedure and the modulation of 5-HT system in the prefrontal cortex. Furthermore, another aim of this study is to investigate the possibility that the combined administration of 5-HT1A receptor antagonist and cholesterol supplementation reverses the induction of depressive symptoms by chronic mild stress.

\section{Methods}

\section{Animals and diets}

Male Sprague-Dawley rats that weighed 200-220 g upon arrival were individually housed under a constant temperature $\left(23 \pm 2^{\circ} \mathrm{C}\right)$ and a $12 \mathrm{~h} / 12 \mathrm{~h}$ light/dark cycle with free access to food and water before the initiation of the experiment. The experimental diet for supplementary cholesterol was provided by the experimental animal centre of our hospital with $1 \mathrm{~g} / \mathrm{kg}$ of cholesterol and sufficient amounts of protein, minerals and vitamins for healthy maintenance. All of the animal procedures were performed in accordance with the National Institutes of Health Guide for the Care and Use of Laboratory Animals, and the procedures were approved by the Local Animal Use Committee. All of the behavioral tests and drug administrations were performed in the dark phase.

\section{Drugs}

The selective 5-HT1A receptors antagonist WAY100635 maleate (Sigma-Aldrich, St. Louis, MO, USA) was dissolved in saline $(0.9 \% \mathrm{NaCl})$. The solutions were prepared immediately before the stress and protected from the light during the experimental sessions. The dose of WAY100635 used for microinjection was selected as $40 \mathrm{nmol} / \mu \mathrm{l}$ based on previous reports [25].

\section{Intracerebral cannula implantation and intracranial injections}

The rats were anesthetized with sodium pentobarbital (60 $\mathrm{mg} / \mathrm{kg}$, i.p.), and guide cannulae (23-gauge, Plastics One, Roanoke, VA, USA) were placed at a $23^{\circ}$ angle toward the midline and implanted bilaterally $1 \mathrm{~mm}$ above the medial prefrontal cortex with the following stereotaxic coordinates: anterior/posterior (A/P), $-3.2 \mathrm{~mm}$; medial/lateral $(\mathrm{M} / \mathrm{L}), \pm$ $2.5 \mathrm{~mm}$; dorsal/ventral (D/V), $-3.3 \mathrm{~mm}[26,27]$. Vehicle, or WAY100635 was intracranially microinjected using $10 \mu \mathrm{l}$ Hamilton syringes (Hamilton, Reno, NV, USA) that were connected via polyethylene-50 tubing to 30 -gauge injectors (Plastics One). A total volume of $0.5 \mu \mathrm{l}$ was infused into each side over $1 \mathrm{~min}$, and the injection syringe was left in place for an additional $1 \mathrm{~min}$ to allow for diffusion. At the end of the experiments, the rats were anesthetized with sodium pentobarbital (100 $\mathrm{mg} / \mathrm{kg}$, i.p.) and transcardially perfused. Cannula placements were assessed using Nissl staining with a thickness of $30 \mu \mathrm{m}$ under light microscopy. Subjects with misplaced cannulae and pathological damage were excluded from the statistical analysis.

\section{Behavioral tests}

\section{Chronic mild stress protocol}

The chronic mild stress protocol was adapted from previous study [28]. Briefly, rats were subjected to different mild stressors for 28 days: Day 1 (cold immobilization for $1 \mathrm{~h}$ at $4^{\circ} \mathrm{C}$, tilted cages $45^{\circ}$ for $24 \mathrm{~h}$ ), Day 2 (immobilization for $1 \mathrm{~h}$, crowding for $24 \mathrm{~h}$ ), Day 3 (forced cold swim for 5 min, soiled bedding for $24 \mathrm{~h}$ ), Day 4 (immobilization for $1 \mathrm{~h}$, vibration for $1 \mathrm{~h}$ ), Day 5 (tilted cages $45^{\circ}$ for $24 \mathrm{~h}$, cold immobilization for $1 \mathrm{~h}$ at $4^{\circ} \mathrm{C}$ ), Day 6 (forced cold swim for $5 \mathrm{~min}$ at $4^{\circ} \mathrm{C}$, crowding for $24 \mathrm{~h}$ ), and Day 7 (vibration for $1 \mathrm{~h}$, soiled bedding for $24 \mathrm{~h}$ ). This schedule was repeated three more times (Table 1). Control rats were handled daily without any stress in the housing room.

\section{Sucrose preference test}

The measurement of sucrose preference was performed as previously described [29]. The rats were trained to adapt to a $1 \%$ sucrose solution $(\mathrm{w} / \mathrm{v})$ for $48 \mathrm{~h}$ at the beginning of the experiment, during which two bottles of $1 \%$ sucrose solution were placed in each cage. After adaptation, rats were deprived of water and food for $24 \mathrm{~h}$, followed by the sucrose preference test, in which the rats were housed in individual cages for $4 \mathrm{~h}$ and had free access to two bottles that contained 1\% sucrose or tap water. The bottles were counterbalanced across the left and right sides of the cages throughout the experiment. 
Table 1 The protocol and stress procedures for chronic mild stress

\begin{tabular}{ll}
\hline Date & Stressor \\
\hline Monday & Cold immobilization for $1 \mathrm{~h}$ at $4^{\circ} \mathrm{C}$, tilted cages $45^{\circ}$ for $24 \mathrm{~h}$ \\
Tuesday & Immobilization for $1 \mathrm{~h}$, crowding for $24 \mathrm{~h}$ \\
Wednesday & Forced cold swim for 5 min, soiled bedding for $24 \mathrm{~h}$ \\
Thursday & Immobilization for $1 \mathrm{~h}$, vibration for $1 \mathrm{~h}$ \\
Friday & Tilted cages $45^{\circ}$ for $24 \mathrm{~h}$, cold immobilization for $1 \mathrm{~h}$ at $4^{\circ} \mathrm{C}$ \\
Saturday & Forced cold swim for 5 min at $4^{\circ} \mathrm{C}$, crowding for $24 \mathrm{~h}$ \\
Sunday & Vibration for $1 \mathrm{~h}$, soiled bedding for $24 \mathrm{~h}$ \\
\hline
\end{tabular}

The position of the two bottles was varied every $2 \mathrm{~h}$ during the test. At the end of $4 \mathrm{~h}$, sucrose and water consumption (in milliliters) was measured, and sucrose preference (\%) was calculated as the ratio of sucrose consumption to sucrose plus water consumption.

\section{Forced swim test}

The rats were placed in a $25 \mathrm{~cm}$ diameter $\times 65 \mathrm{~cm}$ height plastic cylinder that was filled to a depth of 30 $\mathrm{cm}$ with $23-25^{\circ} \mathrm{C}$ water for $15 \mathrm{~min}$. The rats were tested $24 \mathrm{~h}$ later. Immobility was defined as the minimum movement required to passively keep the animal's head above the water without other motions. The results are expressed as the time (in seconds) that the animals spent immobile during the 5 min test [30].

\section{Open field test}

The open field test was used to measure locomotor activity as previously described [31]. Briefly, the apparatus consisted of a $75 \mathrm{~cm} \times 75 \mathrm{~cm} \times 40 \mathrm{~cm}$ square arena divided into 25 equal squares $(15 \mathrm{~cm} \times 15 \mathrm{~cm})$ on the floor of the arena. A single rat was placed in the center of the apparatus, and the number of crossings (i.e., entries into adjacent squares) was counted for $5 \mathrm{~min}$.

\section{Measurement of cholesterol levels}

Rats were killed by decapitation after behavioral tests. Their brains were quickly removed, dissected on ice and collected for subsequent cholesterol analysis. Prior to analysis, the brain samples were spun in a speed vacuum dryer (12 mbar; Savant AES 1000) for $24 \mathrm{~h}$ in order to express the individual sterol concentrations relative to the dry weight. The sterols were extracted from the dried tissue by placing in a $1.5 \mathrm{ml}$ mixture of chloroform/methanol (at a $2: 1$ ratio) for $24 \mathrm{~h}$ at $4^{\circ} \mathrm{C}$. Sterol levels were determined by a gas chromatograph mass spectrometer as described previously [32,33]. The blood samples were kept at room temperature for $1 \mathrm{~h}$ and then centrifuged at $3000 \mathrm{rpm}$ for $10 \mathrm{~min}$. The serum supernatant fraction was stored in another tube for the subsequent cholesterol assays.

\section{Tissue sample preparation}

The rats were decapitated, and the brains were extracted based on our previous study [34]. Subsequently, bilateral tissue punches of the prefrontal cortex and hippocampus (16 gauge) were obtained from approximately $1 \mathrm{~mm}$ thick coronal sections cut in a Reichert-Jung 2800 Frigocut $\mathrm{E}$ cryostat at $-20^{\circ} \mathrm{C}$. The rostral faces of the coronal sections were approximately $3.2 \mathrm{~mm}$ for $\mathrm{mPFC}$ and -3.8 $\mathrm{mm}$ for hippocampus from bregma.

\section{Intracerebral cannula implantation and intracranial injections}

The rats were anesthetized with sodium pentobarbital (60 $\mathrm{mg} / \mathrm{kg}$, i.p.), and guide cannulae (23-gauge, Plastics One, Roanoke, VA, USA) were placed at a $23^{\circ}$ angle toward the midline and implanted bilaterally $1 \mathrm{~mm}$ above the medial prefrontal cortex with the following stereotaxic coordinates: anterior/posterior $(\mathrm{A} / \mathrm{P}),-3.2 \mathrm{~mm}$; medial/lateral $(\mathrm{M} / \mathrm{L}), \pm$ $2.5 \mathrm{~mm}$; dorsal/ventral (D/V), $-3.3 \mathrm{~mm}[26,27]$. Vehicle or WAY100635 $(40 \mathrm{nmol} / \mu \mathrm{l})$ was intracranially microinjected using $10 \mu \mathrm{l}$ Hamilton syringes (Hamilton, Reno, NV, USA) that were connected via polyethylene-50 tubing to 30gauge injectors (Plastics One). A total volume of $0.5 \mu \mathrm{l}$ was infused into each side over $1 \mathrm{~min}$, and the injection syringe was left in place for an additional 1 min to allow for diffusion. At the end of the experiments, the rats were anesthetized with sodium pentobarbital (100 mg/kg, i.p.) and transcardially perfused. Cannula placements were assessed using Nissl staining with a thickness of $30 \mu \mathrm{m}$ under light microscopy. Subjects with misplaced cannulae were excluded from the statistical analysis.

\section{Experimental design \\ Experiment 1: effects of chronic mild stress on the cholesterol levels in the brain}

In this section, we used two groups of rats $(n=8$ per group) to observe the possible impact of chronic mild stress on the central levels of cholesterol. One group of rats was subjected to chronic mild stress procedure for consecutive 28 days, while the other group rats were handled normally without any stress during the period. One day after the last stressor on day 29, rats were weighed, and the sucrose preference test, open field test, forced swim test and food intake in $1 \mathrm{~h}$ were measured consequently. After the behavioral tests, rats were killed by decapitation, and brain tissues of medial prefrontal cortex (mPFC) and hippocampus were collected for further cholesterol assay.

\section{Experiment 2: effects of cholesterol supplementation on the depressive-like behavior}

The purpose of this experiment was to investigate whether chronic cholesterol supplementation by daily diets reverses depressive-like behavior induced by chronic mild stress. Four groups of rats ( $n=8$ per group) were 
used in a 2 (control and CMS) $\times 2$ (vehicle and cholesterol) factorial design to test the effect of cholesterol supplementation on the depressive-like behavior. Rats were subjected to CMS or control without any stress for 28 days and received vehicle or cholesterol on the beginning of the stress period. On day 29, the bodyweight was measured, the sucrose preference test, open field test, forced swim test and food intake in $1 \mathrm{~h}$ were performed to determine the possible treatment effects of chronic supplementation of cholesterol.

\section{Experiment 3: role of chronic cholesterol treatment on the cholesterol content in serum and brain}

We further aimed to explore whether cholesterol supplementation alters cholesterol content differentially in medial prefrontal cortex and hippocampus. Four groups of rats ( $n=8$ per group) were used in a 2 (control and CMS $) \times 2$ (vehicle and cholesterol) factorial design to test the effect of supplementation on the cholesterol level. Rats were subjected to CMS or control for 28 days and received vehicle or cholesterol on the initiation of the stress or control period. On day 29, rats were killed by decapitation without behavioral tests, subsequently blood and brain tissues of $\mathrm{mPFC}$ and hippocampus were collected for further cholesterol assay.

\section{Experiment 4: role of 5-HT1A receptor on the behavioral re- sponses of cholesterol}

To determine whether 5 -HT system is involved in the treatment effects of cholesterol, eight groups of rats $(n=8)$ were used for either control or CMS, either vehicle or cholesterol, and either vehicle or WAY100635, respectively. Rats were micro-injected with 5-HT1A receptor antagonist WAY100635 (40 $\mathrm{nmol} / \mu \mathrm{l}$ per side) or vehicle $1 \mathrm{~h}$ before daily cholesterol provision during the 28-day chronic mild stress process. On day 29, the bodyweight was measured, the sucrose preference test, open field test, forced swim test and food intake in $1 \mathrm{~h}$ were performed to determine the regulatory role of 5-HT1A receptor on the behavioral responses of cholesterol.

\section{Data analysis}

The data are expressed as mean \pm SEM and were analyzed using one- or two-way analysis of variance (ANOVA) followed by Tukey's post hoc test (for details, see Results section). In the two-way ANOVA tests, two factors are involved: 1. CMS and non-CMS groups, 2. diet with and without cholesterol treatment. Values of $\mathrm{P}<0.05$ were considered statistically significant.

\section{Results}

Chronic mild stress induced depressive-like behavior in rats Rats subjected to chronic mild stress for 28 days, one of the most valid models of depression, showed anhedonia state as demonstrated by the decrease in sucrose preference $(\mathrm{P}<0.01$, Figure $1 \mathrm{a})$ with on effects on the total water intake (Figure 1b) compared with rats in control group. In the forced swim test, the immobility was significantly increased by chronic mild stress procedure $(\mathrm{P}<0.01$, Figure 1c), suggesting a behavioral despair induced by chronic stress. Additionally, chronic mild stress reduced the locomotor activity of rats in the open field test $(\mathrm{P}<0.01$, Figure $1 \mathrm{~d})$. Furthermore, we also found that chronic mild stress decreased both the bodyweight $(\mathrm{P}<0.01$, Figure $1 \mathrm{e})$ and the food intake $(\mathrm{P}<$ 0.01 , Figure 1f) compared with control rats. These behavioral results suggest that chronic mild stress induced depressive-like behavior in rats.

\section{Chronic mild stress decreased cholesterol levels}

Cholesterol determination revealed that rats in chronic mild stress exposure produced lower cholesterol levels in the medial prefrontal cortex $(\mathrm{P}<0.01$, Figure $2 \mathrm{a})$ but not the hippocampus ( $\mathrm{P}>0.05$, Figure $2 \mathrm{~b}$ ) compared to control rats. These findings suggested that the decreased cholesterol levels in the medial prefrontal cortex might be associated with the induction of depressive-like behavior in the chronic mild stress procedure.

\section{Chronic low dose of cholesterol supplementation prevented depressive-like behavior induced by chronic mild stress}

We further determine whether pre-treatment with cholesterol before daily stress could prevent the development of depressive-like behavior induced by chronic mild stress. A different set of rats was used in this section (Figure 3a). The results showed that cholesterol added in food for 28 days significantly reversed the depressive-like behavior induced by chronic mild stress as indicated by increased sucrose preference $(P<0.05$, Figure $3 b, c)$, decreased immobility $(P<0.01$, Figure $3 \mathrm{~d}$ ) in the forced swim test, increased crossings in the open field test $(\mathrm{P}<0.01$, Figure $3 \mathrm{e})$ and increased bodyweight $(\mathrm{P}<0.05$, Figure $3 \mathrm{f})$ and food intake $(\mathrm{P}<0.01$, Figure $3 \mathrm{~g})$. The analysis of the sucrose preference data revealed a significant effect of CMS $\left(F_{1,28}=66.20, \mathrm{P}<0.001\right)$ and cholesterol $\left(F_{1,28}=6.68, \mathrm{P}<0.05\right)$ and a significant CMS $\times$ cholesterol interaction $\left(F_{1,28}=5.71, \mathrm{P}<0.05\right)$ for sucrose preference. The analysis of immobility in forced swim test showed a significant effect of CMS $\left(F_{1,28}=\right.$ 31.09, $\mathrm{P}<0.001)$ and cholesterol $\left(F_{1,28}=5.69, \mathrm{P}<\right.$ $0.05)$ and a significant CMS $\times$ cholesterol interaction $\left(F_{1,28}=5.30, \mathrm{P}<0.05\right)$. Additionally, the data analysis of crossings in the open field test showed a significant effect of CMS $\left(F_{1,28}=15.71, \mathrm{P}<0.001\right)$ and cholesterol $\left(F_{1,28}=5.46, \mathrm{P}<0.05\right)$ and a significant CMS $\times$ cholesterol interaction $\left(F_{1,28}=5.90, \mathrm{P}<0.05\right)$. Furthermore, the data analysis of bodyweight changes revealed a significant effect of CMS $\left(F_{1,28}=25.99, \mathrm{P}<\right.$ 

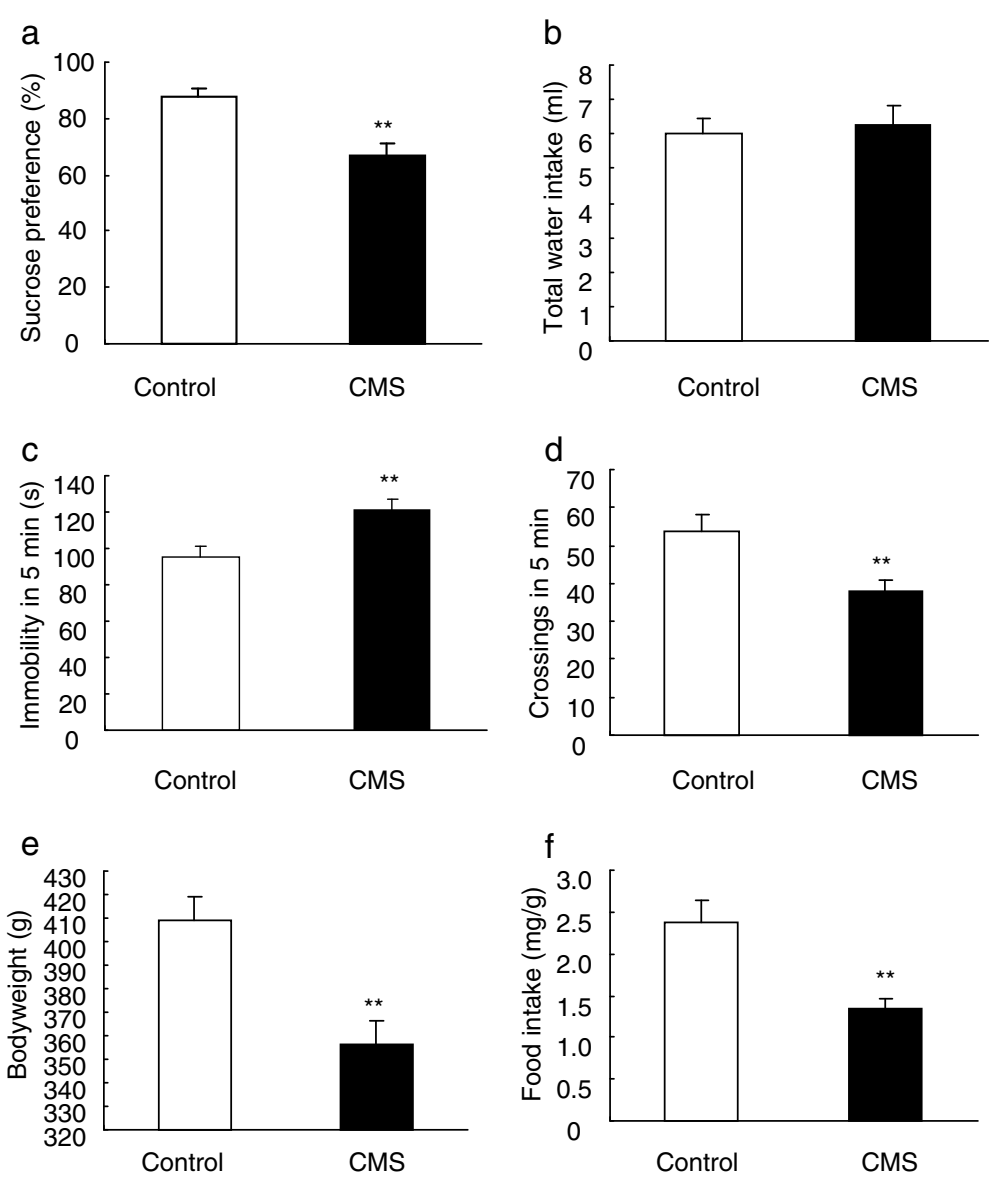

Figure 1 Chronic mild stress induced depressive-like behavior in rats. The behavioral tests were conducted after 28-day chronic mild stress. (a) sucrose preference, (b) total water intake, (c) immobility in the forced swim test, (d) locomotor activity in the open field test, (e) bodyweight, (f) food intake. Data are expressed as mean \pm SEM ( $n=8$ per group). Differences between control and CMS were assessed using Tukey's post hoc test. ${ }^{* *} \mathrm{P}<0.01$ compared with control rats. CMS, chronic mild stress.

a medial prefrontal cortex b hippocampus
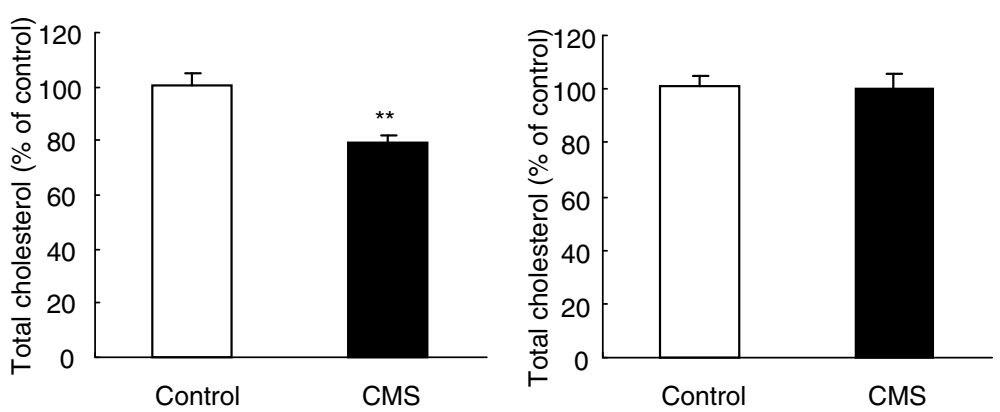

Figure 2 Chronic mild stress decreased cholesterol levels. The levels of cholesterol were significantly decreased by CMS in the medial prefrontal cortex (a) but not in the hippocampus (b). Data are expressed as mean \pm SEM ( $n=8$ per group). Differences between control and CMS were assessed using Tukey's post hoc test. ${ }^{* *} \mathrm{P}<0.01$ compared with control rats. CMS, chronic mild stress. 


\section{a Schemes of experimental schedules}

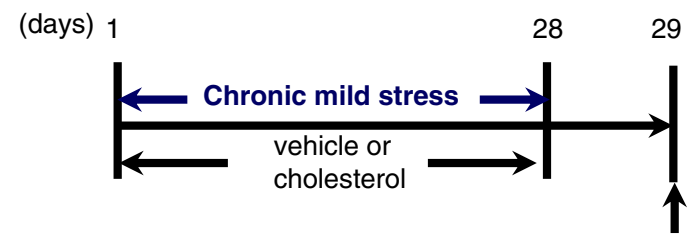

Behavioral tests

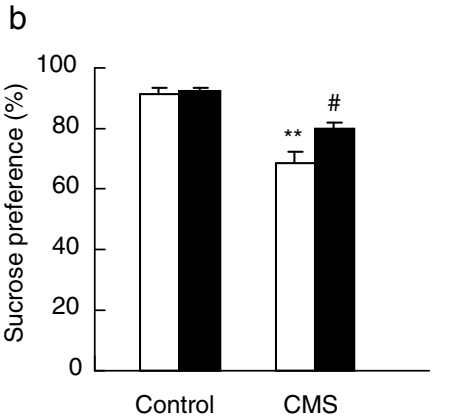

C

d
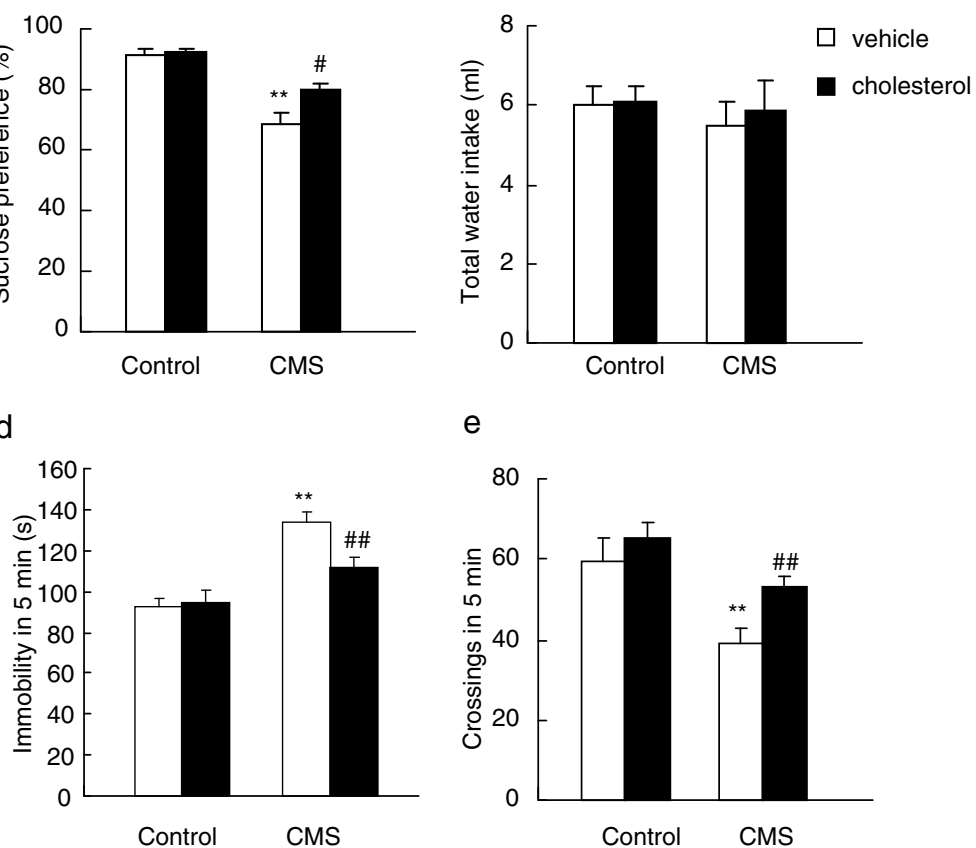

e

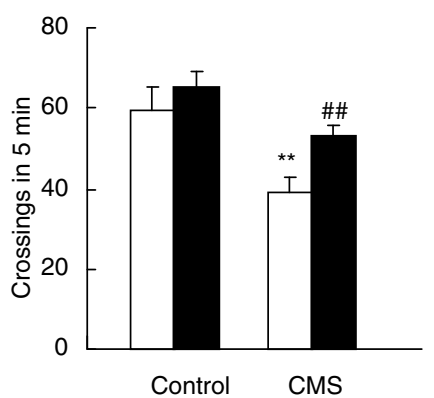

f

g
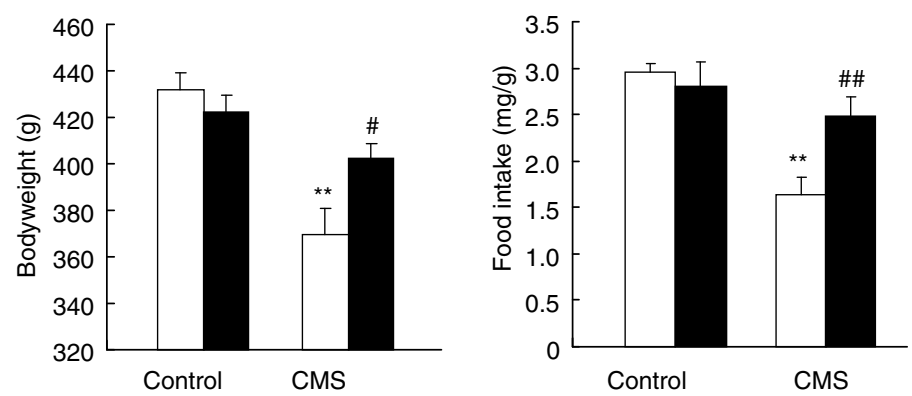

Figure 3 Chronic cholesterol treatment prevented depressive-like behavior induced by chronic mild stress. (a) Schemes of experimental schedules, (b) sucrose preference, (c) total water intake, (d) immobility in the forced swim test, (e) locomotor activity in the open field test,

(f) bodyweight, (g) food intake. Data are expressed as mean \pm SEM ( $n=8$ per group). Differences between control and CMS were assessed using two-way ANOVA followed Tukey's post hoc test. ${ }^{* * P}<0.01$ compared with control rats. ${ }^{\#} \mathrm{P}<0.05,{ }^{\# \#} \mathrm{P}<0.01$ compared with cholesterol-treated chronic mild stress rats.

$0.001)$ and cholesterol $\left(F_{1,28}=6.09, \mathrm{P}<0.05\right)$ and $\mathrm{a}$ significant CMS $\times$ cholesterol interaction $\left(F_{1,28}=7.05\right.$, $\mathrm{P}<0.05)$. Finally, the food intake data analysis showed a significant effect of CMS $\left(F_{1,28}=18.06, \mathrm{P}<0.001\right)$ and cholesterol $\left(F_{1,28}=6.41, \mathrm{P}<0.05\right)$ and a significant $\mathrm{CMS} \times$ cholesterol interaction $\left(F_{1,28}=6.57, \mathrm{P}<0.05\right)$.
These results suggested that cholesterol homeostasis in the central nervous system plays a key role in the depression, especially the stress-related mood disorder. Critical modulation of cholesterol level might be benefit for the treatment and recovery of depressed patients in the clinic. 
Chronic cholesterol treatment increased the cholesterol content in medial prefrontal cortex but not hippocampus It is interesting to find that there is a reduction in cholesterol content in medial prefrontal cortex but not in hippocampus upon subjecting rats to chronic mild stress. Therefore, it is important to clarify whether supplementation alters cholesterol content differentially in these two regions. The results showed that chronic cholesterol treatment for 28 days increased cholesterol content in medial prefrontal cortex (Figure 4a,b) of rats in chronic mild stress. The two-way ANOVA analysis showed a significant effect of CMS $\left(F_{1,28}=25.70\right.$, $\mathrm{P}<0.001)$ and cholesterol $\left(F_{1,28}=5.40, \mathrm{P}<0.05\right)$ and a significant $\mathrm{CMS} \times$ cholesterol interaction $\left(F_{1,28}=6.43\right.$,
$\mathrm{P}<0.05)$ for cholesterol content in the medial prefrontal cortex. However, chronic cholesterol treatment for 28 days did not change the cholesterol content in hippocampus (Figure 4c). In addition, the serum cholesterol content was not altered by cholesterol supplementation (Figure 4d). These findings suggested that increase of cholesterol in medial prefrontal cortex, but not hippocampus, by oral cholesterol supplementation is related to the prevention of depressive-like behavior.

\section{Antagonism of 5-HT1A receptor blocked the behavioral} responses of cholesterol in CMS procedure

To further examine the regulatory role of 5-HT system in the relationship between cholesterol dysfunction and

a Schemes of experimental schedules

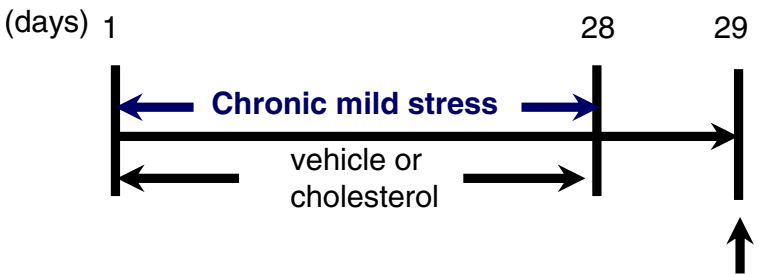

Blood and tissue collection

b medial prefrontal cortex $\mathrm{C}$ hippocampus
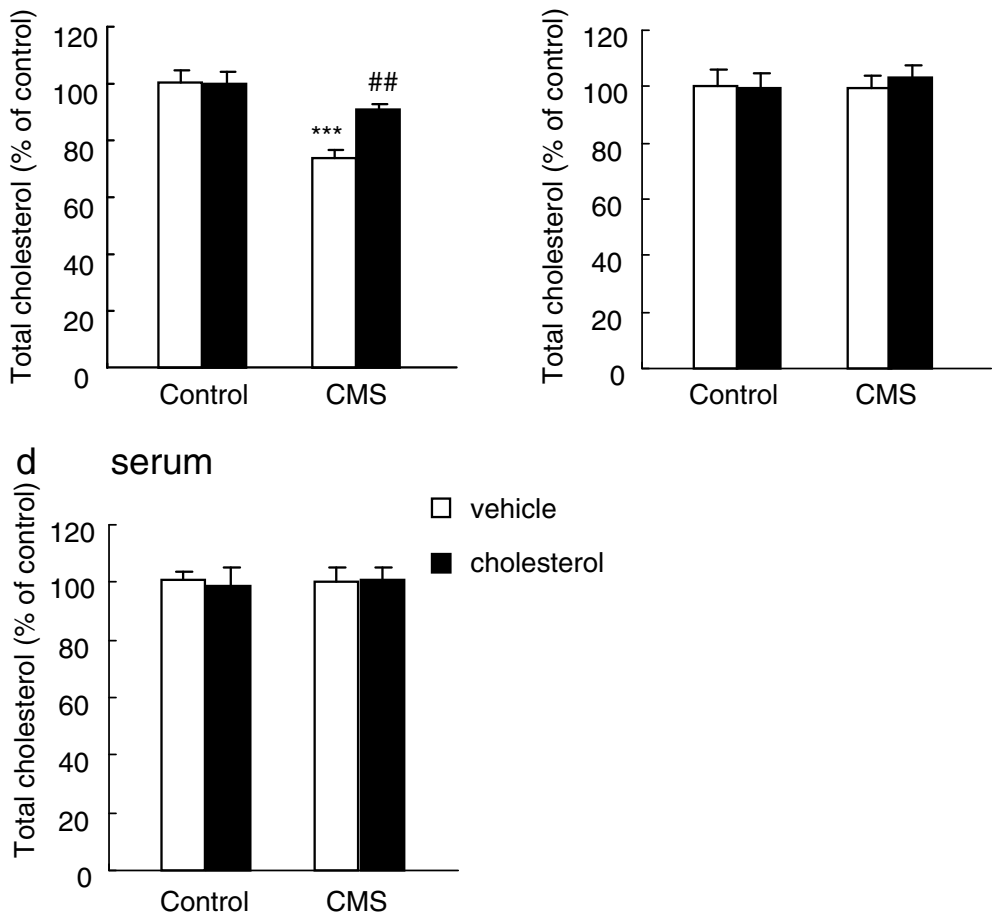

Figure 4 Chronic cholesterol treatment increased the cholesterol content in medial prefrontal cortex but not hippocampus. (a) Schemes and timeline of experimental schedules, Total cholesterol content in (b) medial prefrontal cortex, (c) hippocampus and (d) serum. Data are expressed as mean \pm SEM ( $n=8$ per group). Differences between control and CMS were assessed using two-way ANOVA followed Tukey's post hoc test. ${ }^{* *} \mathrm{P}<0.001$ compared with control rats. ${ }^{\# \#} \mathrm{P}<0.01$ compared with cholesterol-treated chronic mild stress rats. 
a Schemes of experimental schedules

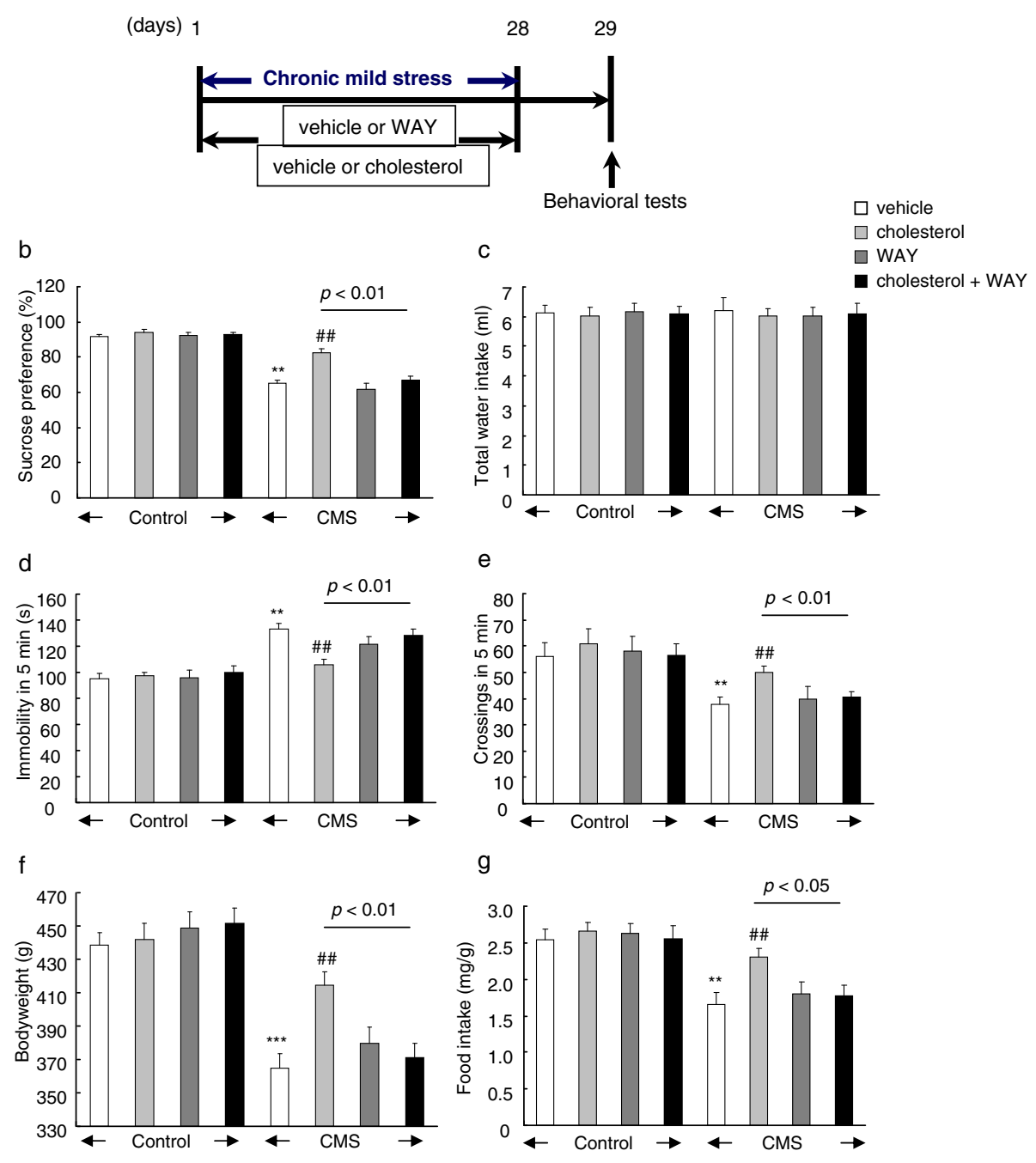

Figure 5 Antagonism of 5-HT1A receptor blocked the behavioral responses of cholesterol in chronic mild stress procedure. (a) Schemes of experimental schedules, (b) sucrose preference, (c) total water intake, (d) immobility in the forced swim test, (e) locomotor activity in the open field test, (f) bodyweight, (g) food intake. Data are expressed as mean \pm SEM ( $n=8$ per group). Differences between control and CMS were assessed using two-way ANOVA followed Tukey's post hoc test. ${ }^{* * P}<0.01$, ${ }^{* * *} \mathrm{P}<0.001$ compared with control rats. ${ }^{\# \# P}<0.01$ compared with cholesterol-treated chronic mild stress rats.

depressive symptoms, we exposed eight groups of rats ( $n=8$ per group) either to chronic mild stress or control administration, and cholesterol or 5-HT1A receptor antagonist WAY100635 was microinjected into the medial prefrontal cortex during 28 days (Figure 5a). One day after the last stressor, we measured the depressive-like behavior of these rats. We found that infusion of WAY100635 significantly reversed the behavioral response of supplementation of cholesterol in the chronic mild stress procedure. Chronic cholesterol provision increased the sucrose preference in stress-treated rats $\left(F_{1,28}=\right.$ 20.81, $\mathrm{P}<0.001$, Figure 5b, c), however, WAY100635 prevented this reversal effects of cholesterol $\left(F_{1,28}=6.51, \mathrm{P}<\right.$ 0.05). Moreover, the reduction of immobility in the forced swim test $\left(F_{1,28}=11.69, \mathrm{P}<0.01\right.$, Figure $\left.5 \mathrm{~d}\right)$ and crossings in the open field test $\left(F_{1,28}=5.19, \mathrm{P}<0.05\right.$, Figure $\left.5 \mathrm{e}\right)$ was also blocked by WAY100635. Similarly, the increased bodyweight $\left(F_{1,28}=10.73, \mathrm{P}<0.01\right.$, Figure $\left.5 \mathrm{f}\right)$ and food intake $\left(F_{1,28}=\right.$ $5.38, \mathrm{P}<0.05$, Figure $5 \mathrm{~g}$ ) was both reversed by WAY100635 microinjection. This finding suggested that cholesterol may have an impact on the sensitivity of the 5-HT receptors in the interactions between stress and depression.

\section{Discussion}

In the current investigation, we found that chronic mild stress induced depressive-like behavior in rats associated with decreased cholesterol levels in the medial prefrontal cortex. However, pre-treatment with cholesterol 
before daily stress could prevent the development of depressive-like behavior induced by chronic mild stress. Finally, intra-mPFC infusion of 5-HT1A receptor antagonist WAY100635 significantly reversed the behavioral response of supplementation of cholesterol in the chronic mild stress procedure. This data suggested that regulation of 5-HT1A receptor participated in the development of depression through control of central cholesterol in rats. In patients with coronary artery disease, the prevalence of several diseases has been increased, such as type 2 diabetes mellitus [35,36] and symptoms of depression [37], leading to increased risk for further cardiac events after acute coronary syndrome. Moreover, about $17 \%-27 \%$ of patients with coronary artery disease have major depression, and a significantly larger percentage have subsyndromal symptoms of depression [38]. Depression has been linked to higher health care costs and to worse outcomes in patients with coronary artery disease $[39,40]$. Selective serotonin reuptake inhibitors (SSRIs) are the first-line antidepressants among patients with coronary artery disease with a lower risk of death/recurrent myocardial infarction [41].

Since low and higher level of serum total cholesterol is a stable feature in some persons with recurrent major depression, the level of total cholesterol in blood samples in patients with major depression has been widely used to estimate the risk of suicidal behavior in the presence of depressive disorder [42]. Consistent with previous findings that serum cholesterol was decreased in depressed patients, our results showed that the cholesterol levels in the medial prefrontal cortex were significantly decreased in rats that were exposed to chronic mild stress for a long period. According to this data, we therefore proposed that the reduced central levels of cholesterol might be related with the onset of depressive-like behavior in rats. However, not all studies suggested a relationship between lower cholesterol and depression. There are some evidences showed that the elevated cholesterol levels were seen in depressed patients [43]. Furthermore, there are strong evidences indicated that serum cholesterol level was increased in patients with coronary artery diseases. However, we focused on the changes of cholesterol level in the central nervous system in our current study. Our data showed cholesterol was decreased in the medial prefrontal cortex, but not in the hippocampus, of the brain in rats exposed to chronic mild stress, which suggested that the alteration of cholesterol in specific brain region might play a different role in the regulation of mood by specific downstream signal pathway. There are many differences between medial prefrontal cortex and hippocampus beyond the number of 5-HT1A receptor. It has been evidenced that chronic mild stress significantly decreased PSD95, a key synaptic protein that co-localizes with
NMDA receptors at synapses, inhibited mTOR function by decreasing phosphorylated p70s6k and rps6 in the medial prefrontal cortex but not hippocampus [44]. Induction of PSD-95 is consistent with increased synapse formation and function. mTOR signaling pathways have been implicated in the increase in synaptic plasticity and new spine formation. Therefore, we raised the possibility that these post-synaptic signal pathways in the medial prefrontal cortex might play a central role in depression symptoms after cholesterol treatment.

The relationship between cholesterol levels, depressive behavior and serotonergic function could be explained that the changed levels of cholesterol are directly responsible for alterations in serotonergic function in depression. Cholesterol is an important membrane lipid and is essential in regulating the properties of cell membranes in mammalian cells organization, dynamics, function, and sorting $[45,46]$.

Several studies showed that chronic administration of stress hormone, such as glucocorticoid corticosterone and adrenocorticotropic hormone, increases muscle tissues and plasma cholesterol in animals $[47,48]$. However, there is no direct evidence revealed the effects of stress on the levels of cholesterol in the central nervous system. Additionally, other abnormalities related to lipid homeostasis described in depressed patients include an increase in the activity of enzymes involved in lipid oxidation and peroxidation [49], lower vitamin E concentrations [50], and lower serum high-density lipoprotein-cholesterol (HDL-C) levels [51]. Previous study showed that simvastatin, a cholesterollowering agent, increased the expression of brain-derived neurotrophin factor (BDNF) and vascular endothelial growth factor (VEGF) in the dentate gyrus (DG) of the hippocampus in rats after traumatic brain injury, suggesting an improvement of cognitive function [52]. Furthermore, pravastatin administration promotes neurological recovery in ischemic stroke animals and induces neurogenesis in the DG and subventricular zone (SVZ), and increases the number of migration cells in the striatum [53]. Cholesterol exists in plasma membrane has been evidence to play an important role in neuronal differentiation, synaptogenesis and axonal guidance [54]. These findings raised the possibility that regulation of cholesterol might play a role on neuroprotection and neurogenesis, which is associated with the stress and depressive disorder. Moreover, serotonin plays a direct and acute regulatory role in activity-dependent hippocampal neurogenesis [55]. Therefore, it could be possible that understanding of cholesterol on the regulation of neurogenesis might offer preventive therapeutic opportunities in depression. Additionally, the changes of cholesterol in serum affect neurotransmission in the central nervous system [10]. The specific neurotransmitter by which cholesterol regulated in the pathophysiology of depression needs further clarification. 
Chronic mild stress significantly reduced 5-HT1A receptor in the prefrontal cortex in rats [56]. Additionally, earlylife stress increased 5-HT1A receptor mRNA expression in the amygdala, and reduced its expression in the dorsal raphé nucleus [57]. These findings suggest that stress induces persistent changes in 5-HT1A receptor and expression in major brain regions involved in the development of stress-related psychiatric disorders. In our current study, we found that intra-mPFC infusion of 5-HT1A receptor antagonist WAY100635 significantly reversed the behavioral response of supplementation of cholesterol in the chronic mild stress procedure. Previous evidence also showed that membrane cholesterol plays a key role in the stability of the human serotonin $(1 \mathrm{~A})$ receptor [58]. It can be presumed that cholesterol binds 5-HT1A receptors [59] and therefore induces translocation to increase serotonin release to counteract depression. Therefore, further studies are required to clarify the cellular mechanisms through which this relationship between cholesterol and depression works.

\section{Conclusion}

In summary, chronic supplementation of cholesterol by food reversed the depressive-like behavior induced by chronic mild stress in rats. Furthermore, pre-injection with 5-HT1A receptor antagonist WAY100635 into the medial prefrontal cortex blocked the treatment effects of cholesterol on the reversal of behavioral response. The present finding revealed that cholesterol may have an impact on the sensitivity of the 5-HT receptors in the interactions between stress and depression. The treatment benefits of cholesterol could be acting through modulation of the brain serotonin system especially in the medial prefrontal cortex.

\section{Competing interests}

The authors declare that they do not have any conflicts of interest.

\section{Authors' contributions}

SS and YS designed this study, SS, MY and JX performed this study, SS and ZZ conducted the data collection and statistic analyses, SS and YS drafted the manuscript. All authors read and approved the final manuscript.

\section{Acknowledgements}

This work was supported in part by the Youth Foundation of the Affiliated Hospital of Qingdao University in 2012

\section{Author details \\ ${ }^{1}$ Department of Geriatric Medicine, The Affiliated Hospital of Qingdao University, 16, Jiangsu Road, Qingdao, Shandong Province 266000, China. ${ }^{2}$ Department of the Intensive Care Unit, The Affiliated Hospital of Qingdao University, 16, Jiangsu Road, Qingdao, Shandong Province 266000, China.}

\section{Received: 30 August 2014 Accepted: 11 March 2015}

Published online: 24 March 2015

\section{References}

1. Balci B. The modification of serum lipids after acute coronary syndrome and importance in clinical practice. Curr Cardiol Rev. 2011;7:272-6.

2. de Jonge P, Rosmalen JG, Kema IP, Doornbos B, van Melle JP, Pouwer F, et al. Psychophysiological biomarkers explaining the association between depression and prognosis in coronary artery patients: a critical review of the literature. Neurosci Biobehav Rev. 2010;35:84-90.

3. Stapelberg NJ, Neumann DL, Shum DH, McConnell H, Hamilton-Craig I. A topographical map of the causal network of mechanisms underlying the relationship between major depressive disorder and coronary heart disease. Aust N Z J Psychiatry. 2011;45:351-69.

4. Maes M, Smith R, Christophe A, Cosyns P, Desnyder R, Meltzer H. Fatty acid composition in major depression: decreased omega 3 fractions in cholesteryl esters and increased C20: 4 omega 6/C20:5 omega 3 ratio in cholesteryl esters and phospholipids. J Affect Disord. 1996;38:35-46.

5. Maes M, Christophe A, Delanghe J, Altamura C, Neels H, Meltzer HY. Lowered omega3 polyunsaturated fatty acids in serum phospholipids and cholesteryl esters of depressed patients. Psychiatry Res. 1999;85:275-91.

6. Fava M, Abraham M, Pava J, Shuster J, Rosenbaum J. Cardiovascular risk factors in depression. The role of anxiety and anger. Psychosomatics. 1996;37:31-7.

7. Partonen T, Haukka J, Virtamo J, Taylor PR, Lonnqvist J. Association of low serum total cholesterol with major depression and suicide. Br J Psychiatry. 1999;175:259-62.

8. Engelberg H. Low serum cholesterol and suicide. Lancet. 1992;339:727-9.

9. Rabe-Jablonska J, Poprawska I. Levels of serum total cholesterol and LDL-cholesterol in patients with major depression in acute period and remission. Med Sci Monit. 2000;6:539-47.

10. Boston PF, Dursun SM, Reveley MA. Cholesterol and mental disorder Br J Psychiatry. 1996;169:682-9.

11. Kaplan JR, Muldoon MF, Manuck SB, Mann JJ. Assessing the observed relationship between low cholesterol and violence-related mortality. Implications for suicide risk. Ann N Y Acad Sci. 1997;836:57-80.

12. Hensler JG. Differential regulation of 5-HT1A receptor-G protein interactions in brain following chronic antidepressant administration. Neuropsychopharmacology. 2002;26:565-73.

13. Middlemiss DN, Price GW, Watson JM. Serotonergic targets in depression. Curr Opin Pharmacol. 2002;2:18-22.

14. Diaz-Mataix L, Scorza MC, Bortolozzi A, Toth M, Celada P, Artigas F. Involvement of 5-HT1A receptors in prefrontal cortex in the modulation of dopaminergic activity: role in atypical antipsychotic action. J Neurosci. 2005;25:10831-43.

15. Bantick RA, De Vries MH, Grasby PM. The effect of a 5-HT1A receptor agonist on striatal dopamine release. Synapse. 2005;57:67-75.

16. Celada P, Bortolozzi A, Artigas F. Serotonin 5-HT1A receptors as targets for agents to treat psychiatric disorders: rationale and current status of research. CNS Drugs. 2013:27:703-16.

17. Paila YD, Murty MR, Vairamani M, Chattopadhyay A. Signaling by the human serotonin(1A) receptor is impaired in cellular model of Smith-Lemli-Opitz Syndrome. Biochim Biophys Acta. 2008;1778:1508-16.

18. Shrivastava S, Pucadyil TJ, Paila YD, Ganguly S, Chattopadhyay A. Chronic cholesterol depletion using statin impairs the function and dynamics of human serotonin(1A) receptors. Biochemistry. 2010;49:5426-35.

19. Drevets WC, Price JL, Furey ML. Brain structural and functional abnormalities in mood disorders: implications for neurocircuitry models of depression. Brain Struct Funct. 2008;213:93-118.

20. MacQueen GM, Yucel K, Taylor VH, Macdonald K, Joffe R. Posterior hippocampal volumes are associated with remission rates in patients with major depressive disorder. Biol Psychiatry. 2008;64:880-3.

21. Miguel-Hidalgo JJ, Rajkowska G. Morphological brain changes in depression: can antidepressants reverse them? CNS Drugs. 2002;16:361-72.

22. Hamani C, Nobrega JN. Preclinical studies modeling deep brain stimulation for depression. Biol Psychiatry. 2012;72:916-23.

23. Meltzer HY, Massey BW, Horiguchi M. Serotonin receptors as targets for drugs useful to treat psychosis and cognitive impairment in schizophrenia. Curr Pharm Biotechnol. 2012;13:1572-86

24. Donaldson ZR, Nautiyal KM, Ahmari SE, Hen R. Genetic approaches for understanding the role of serotonin receptors in mood and behavior. Curr Opin Neurobiol. 2013;23:399-406.

25. Beckett S, Marsden CA. The effect of central and systemic injection of the 5-HT1A receptor agonist 8-OHDPAT and the 5-HT1A receptor antagonist WAY100635 on periaqueductal grey-induced defence behaviour. J Psychopharmacol. 1997;11:35-40.

26. Aguiar DC, Terzian AL, Guimaraes FS, Moreira FA. Anxiolytic-like effects induced by blockade of transient receptor potential vanilloid type 1 (TRPV1) channels in the medial prefrontal cortex of rats. Psychopharmacology (Berl). 2009;205:217-25. 
27. Paxinos G, Watson CR, Emson PC. AChE-stained horizontal sections of the rat brain in stereotaxic coordinates. J Neurosci Methods. 1980;3:129-49.

28. Zhu WL, Shi HS, Wang SJ, Xu CM, Jiang WG, Wang X, et al. Increased Cdk5/ p35 activity in the dentate gyrus mediates depressive-like behaviour in rats. Int J Neuropsychopharmacol. 2012;15:795-809.

29. Willner P, Towell A, Sampson D, Sophokleous S, Muscat R. Reduction of sucrose preference by chronic unpredictable mild stress, and its restoration by a tricyclic antidepressant. Psychopharmacology (Berl). 1987;93:358-64.

30. Porsolt RD, Anton G, Blavet N, Jalfre M. Behavioural despair in rats: a new model sensitive to antidepressant treatments. Eur J Pharmacol. 1978:47:379-91.

31. Lin YH, Liu AH, Xu Y, Tie L, Yu HM, Li XJ. Effect of chronic unpredictable mild stress on brain-pancreas relative protein in rat brain and pancreas. Behav Brain Res. 2005;165:63-71.

32. Jansen PJ, Lutjohann D, Abildayeva K, Vanmierlo T, Plosch T, Plat J, et al. Dietary plant sterols accumulate in the brain. Biochim Biophys Acta. 2006;1761:445-53.

33. Lutjohann D, Brzezinka A, Barth E, Abramowski D, Staufenbiel M, von Bergmann K, et al. Profile of cholesterol-related sterols in aged amyloid precursor protein transgenic mouse brain. J Lipid Res. 2002;43:1078-85.

34. Lu L, Hope BT, Dempsey J, Liu SY, Bossert JM, Shaham Y. Central amygdala ERK signaling pathway is critical to incubation of cocaine craving. Nat Neurosci. 2005:8:212-9.

35. Srinivasan MP, Kamath PK, Manjrekar PA, Unnikrishnan B, Ullal A, Kotekar MF, et al. Correlation of severity of coronary artery disease with insulin resistance. N Am J Med Sci. 2013;5:611-4.

36. Byrkjeland R, Edvardsen E, Njerve IU, Arnesen $H$, Seljeflot I, Solheim S. Insulin levels and HOMA index are associated with exercise capacity in patients with type 2 diabetes and coronary artery disease. Diabetol Metab Syndr. 2014;6:36.

37. McGuire AW, Eastwood JA, Hays RD, Macabasco-O'Connell A, Doering LV. Depressed or not depressed: untangling symptoms of depression in patients hospitalized with coronary heart disease. Am J Crit Care. 2014;23:106-16

38. Rudisch B, Nemeroff CB. Epidemiology of comorbid coronary artery disease and depression. Biol Psychiatry. 2003;54:227-40.

39. Welch CA, Czerwinski D, Ghimire B, Bertsimas D. Depression and costs of health care. Psychosomatics. 2009:50:392-401.

40. Rutledge $T$, Vaccarino V, Johnson BD, Bittner V, Olson MB, Linke SE, et al. Depression and cardiovascular health care costs among women with suspected myocardial ischemia: prospective results from the WISE (Women's Ischemia Syndrome Evaluation) Study. J Am Coll Cardiol. 2009;53:176-83.

41. Ramamurthy G, Trejo E, Faraone SV. Depression treatment in patients with coronary artery disease: a systematic review. Prim Care Companion CNS Disord. 2013;15 Suppl 5:doi:10.4088/PCC.13r01509

42. Kim JM, Stewart R, Kang HJ, Jeong BO, Kim SY, Bae KY, et al. Longitudinal associations between serum cholesterol levels and suicidal ideation in an older Korean population. J Affect Disord. 2014;152-154:517-21.

43. Papakostas GI, Ongur D, losifescu DV, Mischoulon D, Fava M. Cholesterol in mood and anxiety disorders: review of the literature and new hypotheses. Eur Neuropsychopharmacol. 2004;14:135-42.

44. Zhu WL, Wang SJ, Liu MM, Shi HS, Zhang RX, Liu JF, et al. Glycine site $\mathrm{N}$-methyl-D-aspartate receptor antagonist 7-CTKA produces rapid antidepressant-like effects in male rats. J Psychiatry Neurosci. 2013:38:306-16.

45. Simons K, Ikonen E. How cells handle cholesterol. Science. 2000;290:1721-6.

46. Mouritsen OG, Zuckermann MJ. What's so special about cholesterol? Lipids. 2004:39:1101-13.

47. Duan Y, Fu W, Wang S, Ni Y, Zhao R. Cholesterol deregulation induced by chronic corticosterone (CORT) stress in pectoralis major of broiler chickens. Comp Biochem Physiol A Mol Integr Physiol. 2014;176C:59-64.

48. Galman C, Angelin B, Rudling M. Prolonged stimulation of the adrenals by corticotropin suppresses hepatic low-density lipoprotein and high-density lipoprotein receptors and increases plasma cholesterol. Endocrinology. 2002;143:1809-16

49. Bilici M, Efe H, Koroglu MA, Uydu HA, Bekaroglu M, Deger O. Antioxidative enzyme activities and lipid peroxidation in major depression: alterations by antidepressant treatments. J Affect Disord. 2001;64:43-51.

50. Maes M, De Vos N, Pioli R, Demedts P, Wauters A, Neels H, et al. Lower serum vitamin $\mathrm{E}$ concentrations in major depression. Another marker of lowered antioxidant defenses in that illness. J Affect Disord. 2000;58:241-6.
51. Maes M, Smith R, Christophe A, Vandoolaeghe E, Van Gastel A, Neels H, et al. Lower serum high-density lipoprotein cholesterol (HDL-C) in major depression and in depressed men with serious suicidal attempts: relationship with immune-inflammatory markers. Acta Psychiatr Scand. 1997:95:212-21.

52. Wu H, Lu D, Jiang H, Xiong Y, Qu C, Li B, et al. Simvastatin-mediated upregulation of VEGF and BDNF, activation of the PI3K/Akt pathway, and increase of neurogenesis are associated with therapeutic improvement after traumatic brain injury. J Neurotrauma. 2008;25:130-9.

53. Zheng Z, Chen B. Effects of Pravastatin on neuroprotection and neurogenesis after cerebral ischemia in rats. Neurosci Bull. 2007;23:189-97.

54. Guirland C, Zheng JQ. Membrane lipid rafts and their role in axon guidance. Adv Exp Med Biol. 2007;621:144-55.

55. Klempin F, Beis D, Mosienko V, Kempermann G, Bader M, Alenina N. Serotonin is required for exercise-induced adult hippocampal neurogenesis. J Neurosci. 2013;33:8270-5.

56. Szewczyk B, Kotarska K, Daigle M, Misztak P, Sowa-Kucma M, Rafalo A, et al Stress-induced alterations in 5-HT1A receptor transcriptional modulators NUDR and Freud-1. Int J Neuropsychopharmacol. 2014;17:1763-75.

57. Bravo JA, Dinan TG, Cryan JF. Early-life stress induces persistent alterations in 5-HT1A receptor and serotonin transporter mRNA expression in the adult rat brain. Front Mol Neurosci. 2014;7:24.

58. Saxena R, Chattopadhyay A. Membrane cholesterol stabilizes the human serotonin(1A) receptor. Biochim Biophys Acta. 1818;2012:2936-42.

59. Sengupta D, Chattopadhyay A. Identification of cholesterol binding sites in the serotonin1A receptor. J Phys Chem B. 2012;116:12991-6.

\section{Submit your next manuscript to BioMed Central and take full advantage of:}

- Convenient online submission

- Thorough peer review

- No space constraints or color figure charges

- Immediate publication on acceptance

- Inclusion in PubMed, CAS, Scopus and Google Scholar

- Research which is freely available for redistribution 